\title{
Computer-Aided Exergy Sensibility Analysis of Nitrobenzene Production through Benzene Nitration Using an Acid Mixture
}

\author{
Tamy Herrera-Rodríguez, Lina S. Miranda-Jiménez, and Ángel D. González-Delgado \\ Chemical Engineering Department, University of Cartagena, Cartagena de Indias 130015, Colombia \\ Correspondence should be addressed to Ángel D. González-Delgado; agonzalezd1@unicartagena.edu.co
}

Received 14 November 2018; Revised 24 January 2019; Accepted 3 February 2019; Published 3 March 2019

Academic Editor: Jose C. Merchuk

Copyright (c) 2019 Tamy Herrera-Rodríguez et al. This is an open access article distributed under the Creative Commons Attribution License, which permits unrestricted use, distribution, and reproduction in any medium, provided the original work is properly cited.

\begin{abstract}
Nitrobenzene is widely produced via benzene nitration to be applied in several industries such as pharmaceutical, textile, and agricultural. In this work, an exergy sensibility analysis was performed with the aim of identifying possible opportunities of process improvements. The irreversibilities, exergy of wastes, and efficiency were calculated per stage through exergy balance. The simulation software Aspen plus V10.1 provided the physical exergies of process streams while chemical exergies were found in literature. A sensibility analysis was also carried out in order to study the effect of efficiency of some stages (polyfunctional reaction and cooling 1) on global exergy efficiency. This analysis reveals that nitrobenzene production from benzene is an efficient process from an exergy viewpoint (88\%). The total irreversibilities, total exergy of wastes, and exergy of utilities-inlet were calculated in $41,647,341.85 \mathrm{MJ} / \mathrm{h}, 5,537,487.3 \mathrm{MJ} / \mathrm{h}$, and $18,137,363.71 \mathrm{MJ} / \mathrm{h}$, respectively. The results obtained from sensibility analysis suggested that heat flow of heat exchangers HE-201, HE-303, and HE-301 could provide energy requirements for heating.
\end{abstract}

\section{Introduction}

Nitrobenzene is an important compound in chemical processes for producing dyes, leather goods, pharmaceuticals, pesticides, explosives, agricultural chemicals, solvents, and organic synthesis of intermediates [1-3]. The nitration of aromatics is an important electrophilic substitution reaction widely used in the large-scale industrial process of nitroaromatic valuable chemicals such as nitrobenzene, nitrotoluene, and 2,4-dinitrotoluene [4, 5]. Nitrobenzene is commercially produced via nitration of benzene with a mixture of sulfuric and nitric acids, which is an excellent example of reactions in the liquid phase [6,7]. The sulfuric acid acts as a homogeneous nitration catalyst and at the same time as a dehydrating agent protonating the $\mathrm{HNO}_{3}$ molecules, while nitric acid acts as the main nitration agent $[8,9]$. This reaction occurs quickly and is highly exothermic; hence, temperature must be controlled to avoid formation of more by-products, decomposition of nitric acid, and even explosion [10].

The nitration of benzene is commonly used because of its high efficiency; however, it is not environment friendly due to the huge amount of acid wastes generated in this hazardous industrial process, which include diluted sulfuric acid (0.9 ton wastes per 1 ton of commercial products) obtained after reaction and formation of water and nitrophenols formed as by-products $[8,11,12]$. To overcome these drawbacks, many efforts have been made on developing improvements involving lower energy consumption and various clean nitration approaches [13]. To date, exergy analysis tool has not been employed to identify process stages that need to be enhanced from an energy viewpoint. This work is focused on performing exergy sensibility analysis to nitrobenzene production through benzene nitration as the heterogeneous liquid-liquid catalyzed reaction using sulfuric and nitric acids solution in order to analyze global irreversibilities and propose a novel alternative to increase global exergy efficiency.

\section{Materials and Methods}

2.1. Process Description. The nitrobenzene is produced via nitration of benzene using a mixture of concentrated acids 
[14]. The sulfuric acid medium acts as a catalyst and dehydrating agent that bonds with water to ensure that all of the nitric acid is employed for nitration [8,9]. Some of the reactives (streams 1,2, and 4) are transported from storage tanks to the adiabatic mixer using a pump. During the mixing, an exothermic reaction takes places; the rise in temperature is due to the enthalpy of mixing, and the output stream is increased to $120^{\circ} \mathrm{C}$, which is constituted by the components listed in Table 1. A heat exchanger is used to cool this stream (stream 6) to a target temperature of $80^{\circ} \mathrm{C}$.

The process block diagram for the nitrobenzene manufacturing plant via benzene nitration is shown in Figure 1. As can be observed, this process involves 18 stages that are described as follows: the catalyzed liquid-liquid reaction is carried out in four adiabatic reactors achieving conversions of $91 \%$ (stream 9), 98\% (stream 10), 99\% (stream 11), and $99.5 \%$ (stream 12) for reactors 1, 2, 3, and 4, respectively. The catalyst is in a different phase as benzene is an organic reactant and the mixed acid is in the aqueous phase; hence, it is a heterogeneous catalyst. The high purity benzene (stream 8 ) enters the first reactor in excess in order to react with all of the nitric acid. This stage requires continuous stirring to keep the benzene, nitric acid, and sulfuric acid well mixed [15]. The nitric acid acts as the main nitration agent, and the sulfuric acid protonates the $\mathrm{HNO}_{3}$ molecules generating active electrophilic species that attack the aromatic ring. The nitration reaction is described as follows [9]:

$$
\mathrm{HNO}_{3}+2 \mathrm{H}_{2} \mathrm{SO}_{4} \leftrightarrow \mathrm{NO}_{2}^{+}+\mathrm{H}_{3} \mathrm{O}^{+}+2 \mathrm{HSO}_{4}^{-}
$$

As can be analyzed from this reaction, the nitronium ion $\left(\mathrm{NO}_{2}{ }^{+}\right)$is obtained by dissociation of nitric acid in the presence of sulfuric acid reaction [16]. The overall reaction scheme is shown in Figure 2.

The stream leaves the fourth reactor at $135.75^{\circ} \mathrm{C}$ and is fed into a heat exchanger to cool it until $80^{\circ} \mathrm{C}$ (stream 13). A separator is employed to remove the sulfuric acid solution (stream 14) from the organic phase (stream 19). The sulfuric acid solution is purified using an evaporator in order to send it back to the mixer. The organic phase is sent to a centrifugal extractor, in which sodium carbonate is used as the extracting agent (stream 22). The resulting wastes (stream 23) are sent to the environmental treatment unit. The stream leaving the extractor passes through a stripping column that is employed to separate benzene from nitrobenzene with steam. The water content in the benzene stream is removed in a liquid-liquid separator. The purified benzene is cooled and sent back to the first reactor.

\subsection{Exergy Analysis. The exergy analysis represents a} powerful tool to overcome the limitations of the first law of thermodynamics, allowing to identify the main sources of energy loss and improve process efficiency $[17,18]$. In addition, this analysis has been widely used to measure the sustainability of industrial processes [19]. Exergy is defined as the maximum theoretical useful work obtained when a system is brought into thermodynamic equilibrium with its environment [20]. The exergy transfer by heat flow at
TABLE 1: Composition of the mixer output stream.

\begin{tabular}{lc}
\hline Component & Mass fraction \\
\hline Nitric acid & 5.2 \\
Sulfuric acid & 62.5 \\
Steam & 32.2 \\
\hline
\end{tabular}

temperature $T\left(\dot{\mathrm{Ex}}_{\text {heat }}\right)$ and exergy by work flow $\left(\dot{\mathrm{EX}}_{\text {work }}\right)$ was calculated by the following equation:

$$
\begin{aligned}
\dot{\mathrm{Ex}}_{\text {heat }} & =\left(1-\frac{T_{\mathrm{o}}}{T}\right) \cdot \dot{Q}, \\
\dot{\mathrm{E}} \mathrm{x}_{\text {work }} & =\dot{W} .
\end{aligned}
$$

The mass exergy component is divided into physical exergy $\left(\dot{\mathrm{E}} \mathrm{x}_{\text {phy }}\right)$, chemical exergy $\left(\dot{\mathrm{Ex}}_{\text {che }}\right)$, potential exergy $\left(\dot{\mathrm{Ex}}_{\mathrm{pot}}\right)$, and kinetic exergy $\left(\dot{\mathrm{Ex}}_{\mathrm{kin}}\right)$, as shown in the following equation:

$$
\dot{\mathrm{E}} \mathrm{x}_{\text {mass }}=\dot{\mathrm{E}} \mathrm{x}_{\mathrm{phy}}+\dot{\mathrm{E}} \mathrm{x}_{\text {che }}+\dot{\mathrm{E}} \mathrm{x}_{\text {pot }}+\dot{\mathrm{E}} \mathrm{x}_{\mathrm{kin}} .
$$

The potential and kinetic exergy were considered negligible. The chemical exergy was calculated in the following equation:

$$
\dot{\mathrm{Ex}} \mathrm{x}_{\text {che }}=\Delta G_{f}^{0}+\sum v_{i} \mathrm{Ex}_{\mathrm{ch}-i}^{0},
$$

where $\dot{\mathrm{Ex}}_{\mathrm{ch}-i}^{0}$ is the chemical exergy of each elemental compound, $\Delta G_{f}^{0}$ is the Gibbs free energy of formation for the compound, and $v_{i}$ is the number of atoms of each element contained into the stream. The chemical exergy of process streams was determined as follows:

$$
\dot{\mathrm{Ex}}_{\mathrm{che}, \text { mix }}=\sum y_{i} * \mathrm{Ex}_{\mathrm{ch}-i}^{0}+\mathrm{RT}_{0} \sum y_{i} * \ln y_{i},
$$

where $y_{i}$ is the molar fraction of component $i, T_{0}$ is the reference temperature, and $R$ is the gas constant. In this work, chemical exergy of some compounds was found in literature and used to perform exergy analysis [21]. The physical exergy is defined as

$$
\dot{\mathrm{E}} \mathrm{x}_{\text {phy }}=\left(H-H_{0}\right)-T_{0}\left(S-S_{0}\right) \text {. }
$$

For an ideal gas with constant heat capacity, the physical exergy can be also calculated by equation (7). For a solidliquid mixture, it is defined by equation (8), where $C_{\mathrm{p}}$ is the heat capacity, $v_{\mathrm{m}}$ is the molar volume, $T$ is the operating temperature, $P_{0}$ is the reference pressure, and $P$ is the operating pressure:

$$
\begin{array}{r}
\dot{\mathrm{Ex}}_{\mathrm{phy}}=C_{\mathrm{p}}\left(T-T_{0}\right)-T_{0}\left(C_{\mathrm{p}} \ln \frac{T}{T_{0}}-R \ln \frac{P}{P_{0}}\right), \\
\dot{\mathrm{Ex}}_{\text {phy-liq-sol }}=C_{\mathrm{p}}\left[\left(T-T_{0}\right)-T_{0} \ln \frac{T}{T_{0}}\right]-v_{\mathrm{m}}\left(P-P_{0}\right) .
\end{array}
$$

The physical exergy for each process stream was provided by Aspen plus V10.1 simulation software considering operating conditions as pressure, temperature, and composition. The UNIQUAC model and Peng-Robinson equation of states were used to simulate thermodynamic properties of compounds. 


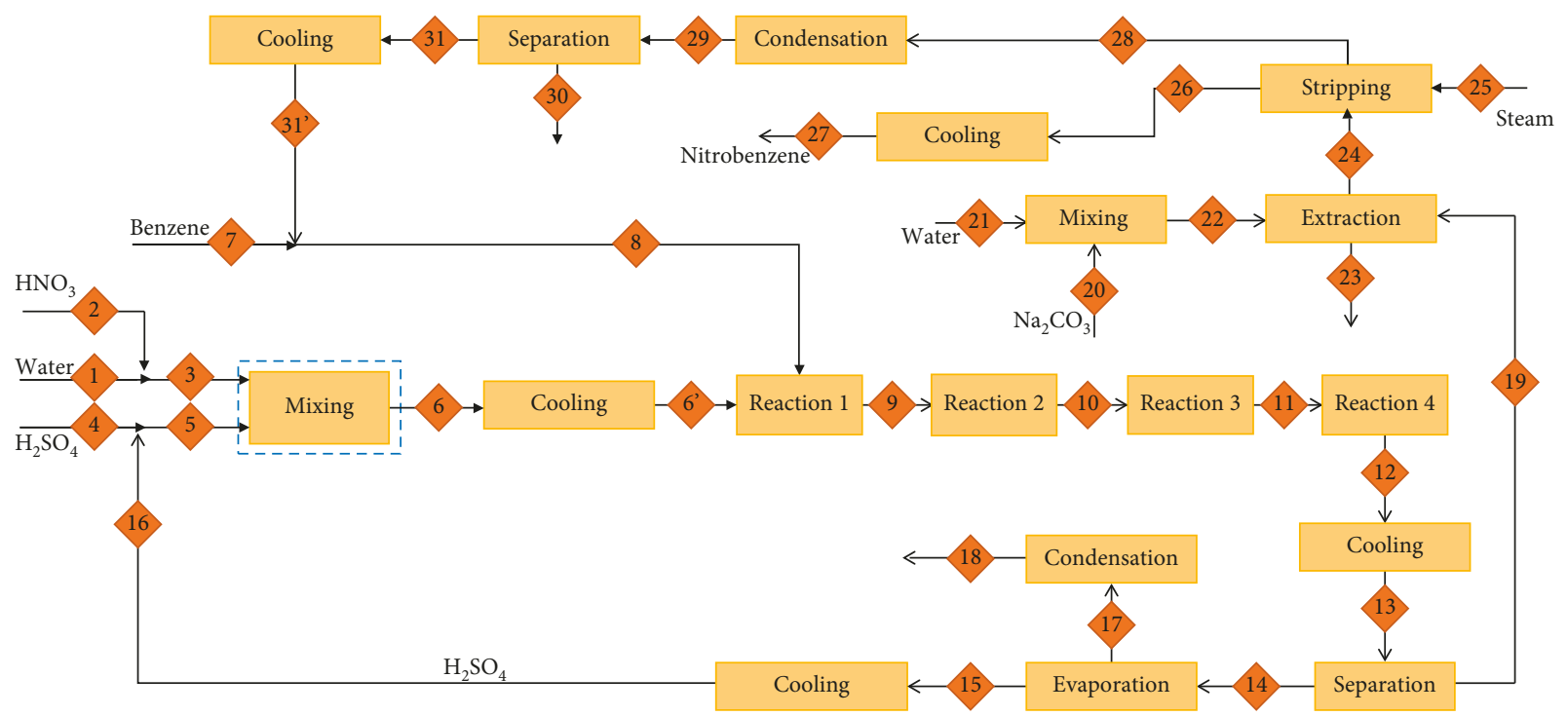

FIGURE 1: Block diagram of nitrobenzene production via benzene nitration.

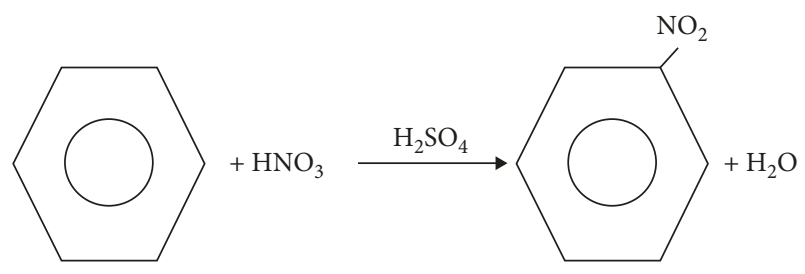

FIgURE 2: Benzene reaction to nitrobenzene.

The exergy balance equation involves the exergy that enters the system by stream $\left(\dot{\mathrm{Ex}} \mathrm{mass}_{\text {-in }}\right)$ or utilities $\left(\dot{\mathrm{Ex}}_{\text {utilities-in }}\right)$ :

$$
\dot{\mathrm{E}} \mathrm{x}_{\mathrm{in}}=\dot{\mathrm{E}} \mathrm{x}_{\text {mass-in }}+\dot{\mathrm{E}} \mathrm{x}_{\mathrm{utilities}-\mathrm{in}}
$$

The output of exergy is attributed to products or residues generated during the manufacturing process, which is shown as follows:

$$
\dot{\mathrm{E}} \mathrm{x}_{\text {out }}=\sum \dot{\mathrm{E}} \mathrm{x}_{\text {product-out }}+\sum \dot{\mathrm{E}} \mathrm{x}_{\text {residues-out }} \text {. }
$$

A global balance around the system allows to calculate the process irreversibilities that indicate the unused potential work:

$$
\dot{\mathrm{Ex}} \mathrm{loss}_{\text {los }}=\sum \dot{\mathrm{E}} \mathrm{x}_{\mathrm{in}}+\sum \dot{\mathrm{E}} \mathrm{x}_{\text {product-out }} .
$$

The exergy efficiency of the process and the contribution of each stage to exergy loss were calculated by the following equations, respectively:

$$
\begin{aligned}
n_{\text {exergia }} & =1-\left(\frac{\dot{\mathrm{E}} \mathrm{x}_{\text {loss }}}{\sum \dot{\mathrm{E} \mathrm{x}_{\mathrm{in}}}}\right), \\
\% \dot{\mathrm{Ex}}_{\mathrm{loss}, i} & =1-\left(\frac{\dot{\mathrm{E}} \mathrm{x}_{\text {loss }, i}}{\sum \dot{\mathrm{E}} \mathrm{x}_{\mathrm{in}}}\right) * 100 \% .
\end{aligned}
$$

Assumptions. The following assumptions were considered to successfully perform exergy analysis: (i) A polyfunctional reactor was incorporated to synthesize the four reactors, a heat exchanger, and a separator, as shown in Figure 3

(ii) Heat flow was supplied to the mixer in order to have zero irreversibilities

(iii) The evaporator was combined with a heat exchanger and represented as a new single stage

\section{Results and Discussion}

3.1. Exergy Analysis. The exergy balance around the system provides information concerning the efficiency of process stages and allows to identify promising improvements. Table 2 summarizes the chemical and physical exergy of process streams, which were calculated using both mathematical equations and simulation software.

The exergy analysis revealed that the condenser (C-301Condensation 1) employed after the extraction process exhibited the highest exergy of residues because of the amount of water used to cool stream 17 . The extraction stage also reported a high value for exergy of wastes followed by the separation stage, which was expected due to the amount of sodium carbonate, sulfuric acid, and water that are removed from the main stream (stream 19). The results in the separation stage were attributed to the $4155 \mathrm{~kg} / \mathrm{h}$ of water considered as wastes and removed to obtain pure benzene. Figure 4 shows the irreversibilities, percentage of destroyed exergy, exergy efficiency, and exergy of wastes in each process stage. As can be observed, the highest percentage of destroyed exergy (45.6\%) was achieved in the cooling 1 stage (HE-201-202) incorporated for reducing the temperature of the mixed acid stream, followed by polyfunctional reaction with $32.36 \%$. Many stages showed exergy efficiency around $100 \%$ including mixing, evaporation, extraction, stripping, and separation. Hence, improvements are required in the other stages in order to increase exergy efficiency. 


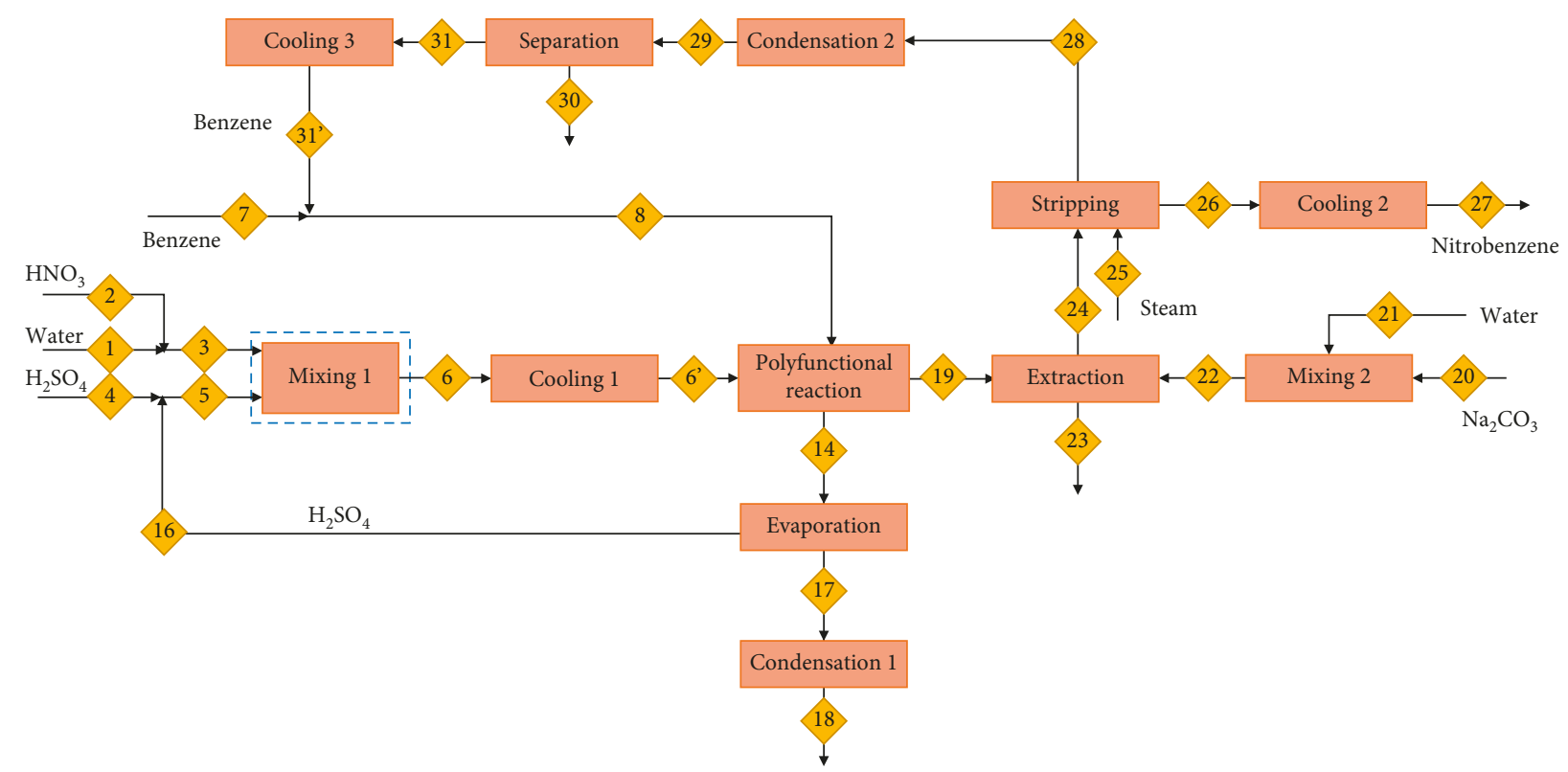

Figure 3: Simplified block diagram of nitrobenzene production via benzene nitration.

TABLE 2: Chemical and physical exergy of process streams.

\begin{tabular}{lccccc}
\hline Stream & Chemical exergy $(\mathrm{MJ} / \mathrm{h})$ & Physical exergy $(\mathrm{MJ} / \mathrm{h})$ & Stream & Chemical exergy $(\mathrm{MJ} / \mathrm{h})$ & Physical exergy $(\mathrm{MJ} / \mathrm{h})$ \\
\hline 1 & 41,713 & 0 & 17 & $4,589,949.70$ & $2,563.07$ \\
2 & $4,030,344$ & 0 & 18 & $4,589,949.70$ & $2,481.18$ \\
3 & $3,990,556$ & 0 & 19 & $358,369,816$ & 137.944 \\
4 & $635,381.8$ & 0 & 20 & $176,954.46$ & 0 \\
5 & $123,897,699$ & 0 & 21 & $163,513.4$ & 0 \\
6 & $146,083,466$ & $10,350.6$ & 22 & $265,086.56$ & 0 \\
$6^{\prime}$ & $127,097,215$ & $6,824.42$ & 23 & $767,249.69$ & 6.73 \\
7 & $334,304,985$ & 0 & 24 & $357,901,218$ & 207.38 \\
8 & $369,388,411$ & 0 & 25 & $2,157,138$ & 186.86 \\
9 & $502,446,269$ & $13,920.2$ & 26 & $322,890,467$ & 15.77 \\
10 & $501,947,287.1$ & $14,510.5$ & 28 & $37,23 E+068,405.19$ & 95.01 \\
11 & $501,679,934$ & $14,592.6$ & 29 & $35,089,089$ & 58.33 \\
12 & $501,719,536$ & $14,632.1$ & 30 & $177,741.67$ & 5.67182 \\
13 & $481,857,776$ & $5,513.99$ & 31 & $35,052,665$ & 0 \\
14 & $124,641,474$ & $5,674.97$ & $31^{\prime}$ & $35,052,665.3$ & \\
15 & $140,468,450$ & $15,567.4$ & & & \\
16 & $123,266,375.1$ & 0 & & \\
\hline
\end{tabular}

Figure 5 shows global exergy efficiency, total exergy of wastes, total irreversibilities, and total exergy of utilities. As can be observed, the nitrobenzene production process exhibited a global efficiency of $88 \%$, indicating a good conversion of the raw material into the desired products. The total irreversibilities and exergy of wastes were calculated in $41,647,341.85$ and 5,537,487.3 MJ/h, respectively. In order to improve this process from an exergetic viewpoint, some streams of wastes could be used. The composition of stream 18 is 0.98 of water and 0.02 of a mixture constituted by nitric acid, benzene, and nitrobenzene. Hence, water content can be recovered and used for cooling or heating requirements.

3.2. Sensibility Analysis. An exergy sensibility analysis was performed in order to evaluate the effect of irreversibilities and exergy efficiencies of stages on global process efficiency. As is shown in Figure 6, the global exergy efficiency increased by $4 \%$ as exergy efficiency of the polyfunctional reaction stage varied from $68 \%$ to $95 \%$. Figure 7 shows an increase in global exergy efficiency as the efficiency of heat exchangers HE-201 and HE-202 increased from 54\% to 95\%.

In order to identify how process efficiency may be improved, it was assessed how the conversion in each of the four reactors may affect the exergy efficiency of the stage. Hence, the exergy of products leaving the reactors was calculated and plotted along with the cumulative conversion. As shown in Figure 8, the exergy of streams leaving the reactors decreased as the number of reactors increased, i.e., both variables have an inverse relationship, which is attributed to the lower exergy value for products compared to the exergy of reactives. The exergy of products also 


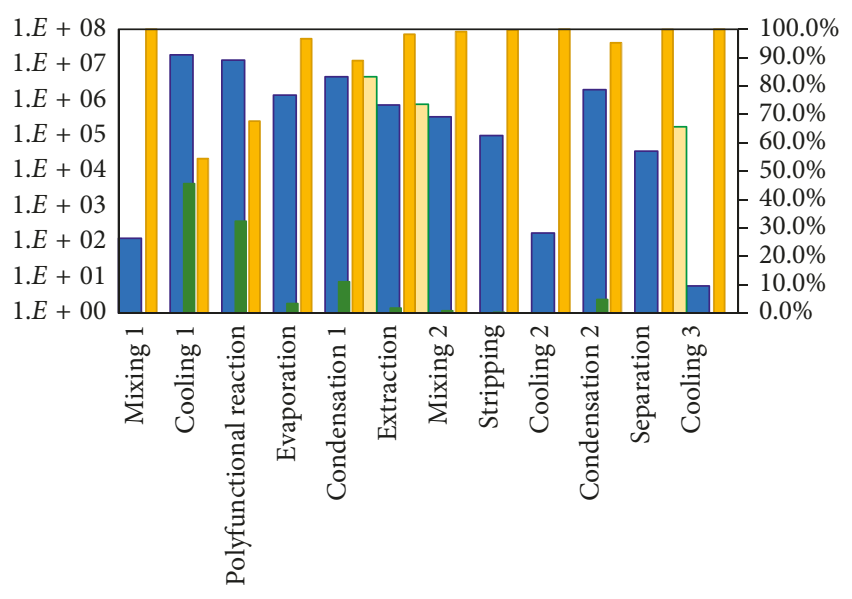

- Irreversibilities $(M J / h)$

- Exergy of wastes $(\mathrm{MJ} / \mathrm{h})$

- Destroyed exergy (\%)

- Exergy efficiency (\%)

FIGURE 4: Exergy analysis results per process stage.

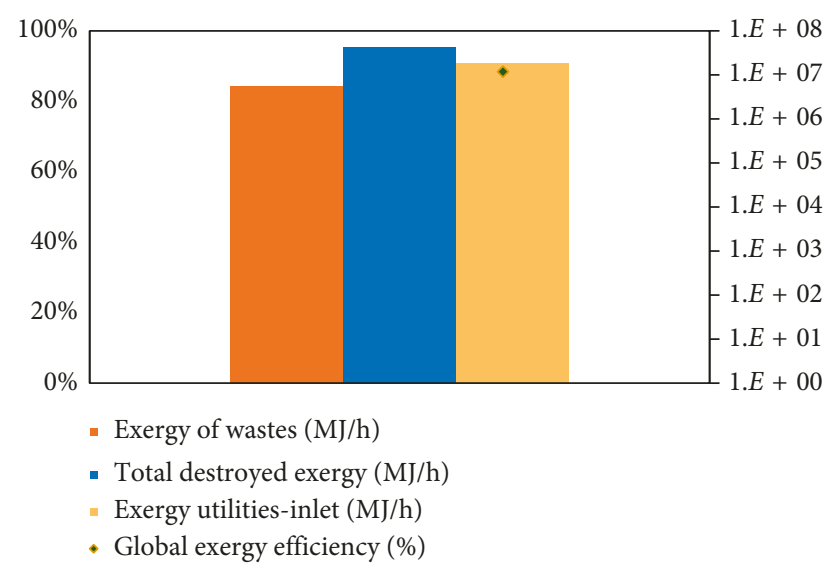

FIGURE 5: Global exergy analysis results for nitrobenzene production.

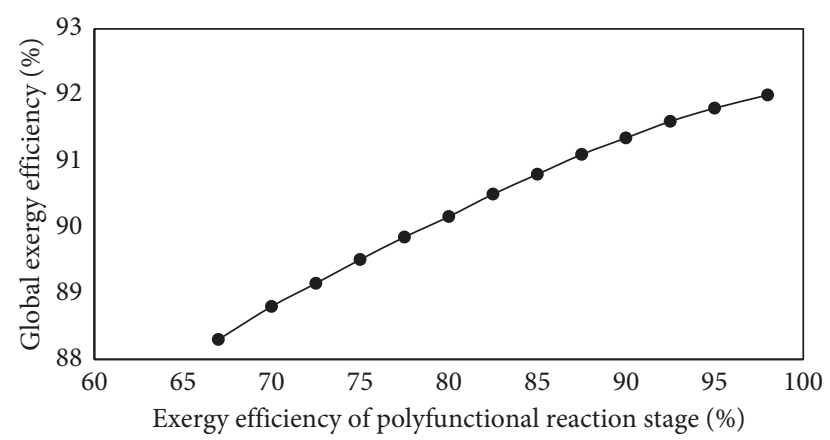

Figure 6: Effect of the polyfunctional reaction stage efficiency on global exergy efficiency.

represents a measure of exergy performance because it obtained higher irreversibilities for lower values of exergy of products, affecting the exergy efficiency of this stage.

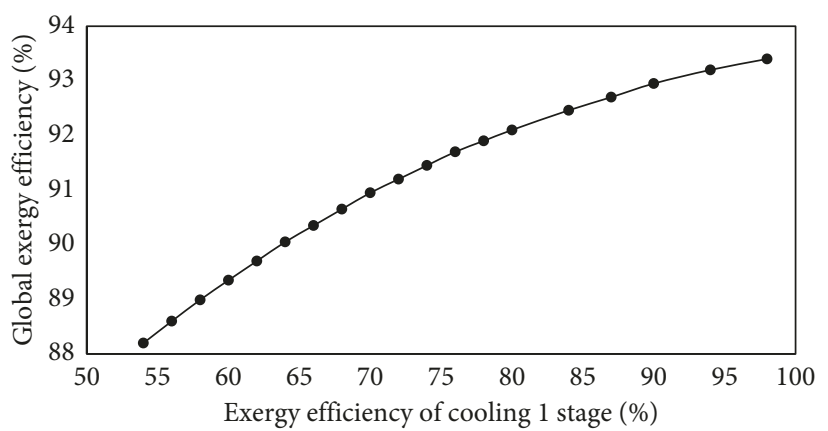

Figure 7: Effect of cooling 1 (HE-201-202) stage efficiency on global exergy efficiency.

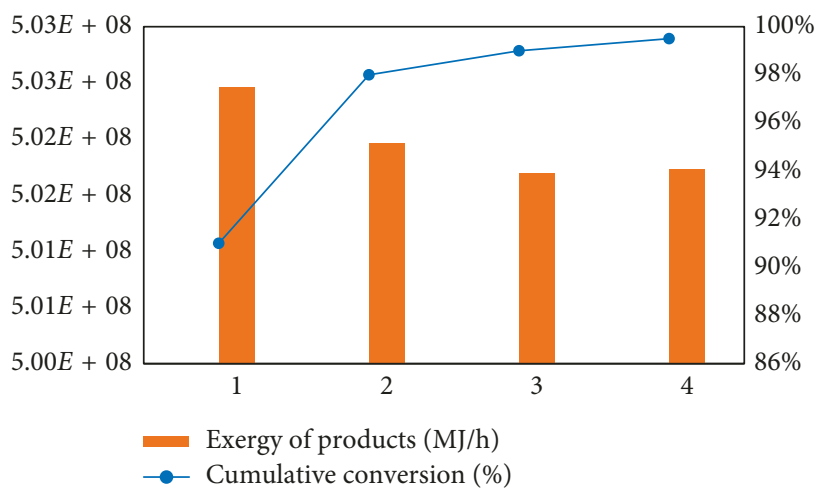

FIGURE 8: Effect of reactors number on the exergy performance of the polyfunctional reaction stage.

The sensibility analysis in Figure 6 shows a 4\% increase in global exergy efficiency based on an increase in the exergy of the polyfunctional reaction stage. However, this stage is composed of four reactors, heat exchanger, and separator, and the contribution of these unit operations to the stage exergy efficiency needs to be assessed. Figure 9 presents the contribution of each unit operation to the irreversibilities of the polyfunctional reaction stage. It was found that the separation unit affects significantly the irreversibilities of the stage, representing $96 \%$ of total irreversibilities, followed by cooling (3.9\%) and reaction ( $0.8 \%)$. According to these results, there is a need to improve the separation unit in this stage. This contribution is directly related to the separation efficiency because a change in separation efficiency affects the exergy of wastes. On the contrary, contributions of the cooling unit are given by the lack of equipment for heat recovery and use (heat integration). Finally, the low contribution of the reaction stage is given by the efficient use of energy through the use of adiabatic reactors which allow to take advantage of the heat released by the reaction for heating the outlet stream in each reactor increasing conversion.

Figure 10 shows the heat flow in heat exchangers HE201, HE-301, HE-303, HE-501, and HE-502, which were employed in the stages of cooling 1, polyfunctional reaction, evaporation, cooling 2 , and cooling 3 , respectively. As is observed, the HE-201, HE-303, and HE-301 exhibited the highest output heat flow that could be used to supply the heating requirements of other process streams. 


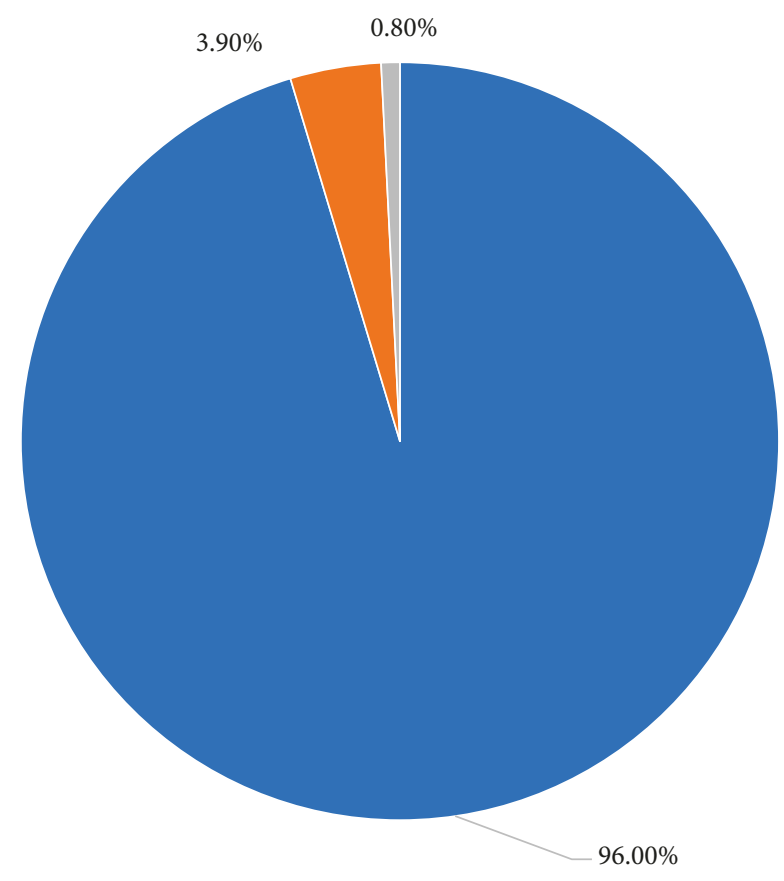

Separation

Cooling

Reaction

Figure 9: Contribution of unit operations to the irreversibilities of the polyfunctional reaction stage.

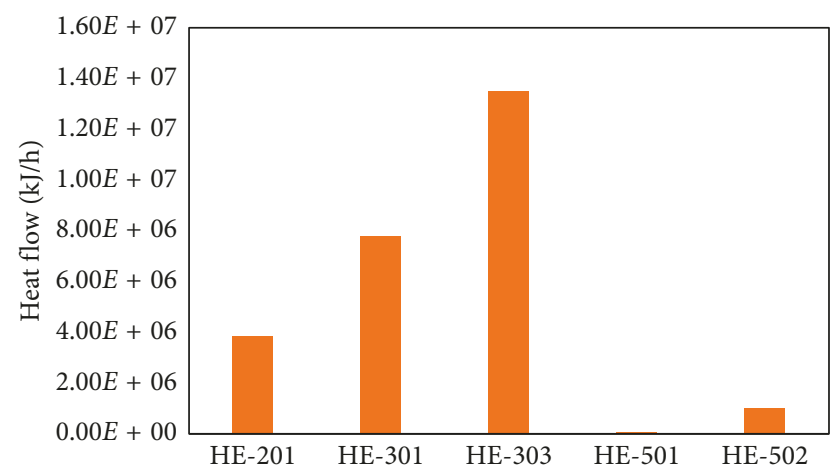

Figure 10: Output heat flow in heat exchangers.

\section{Conclusions}

An exergy analysis was carried out by the nitrobenzene production process via benzene nitration in order to identify stages with high irreversibilities and propose suitable alternative to improve global exergy efficiency. The global efficiency was calculated in $88 \%$ attributed to the few wastes streams as a result of good conversion of raw materials into desired products. The highest irreversibilities were found in the cooling 1 stage, followed by the polyfunctional reaction stage. This process reported total irreversibilities, total exergy of wastes, and exergy of utilities-inlet of 41,647,341.85 MJ/h, 5,537,487.3 MJ/h, and 18,137,363.71 MJ/ $\mathrm{h}$, respectively. It was proposed to use the heat flow of heat exchangers HE-201, HE-303, and HE-301 to provide energy requirements for heating.

\section{Data Availability}

Previously reported research articles data were used to support this study and are available at ScienceDirect. These prior studies (and datasets) are cited at relevant places within the text as references.

\section{Conflicts of Interest}

The authors declare that they have no conflicts of interest.

\section{Acknowledgments}

The authors thank the University of Cartagena for providing software required to carry out this work.

\section{References}

[1] Q. Liu, H.-Q. Zhao, L. Li et al., "Effect of surface modification on carbon nanotubes (CNTs) catalyzed nitrobenzene reduction by sulfide," Journal of Hazardous Materials, vol. 357, pp. 235-243, 2018.

[2] M. Liu, T. Zhang, H. Ren et al., "Nitrogen-doped hollow carbon nanospheres for highly sensitive electrochemical sensing of nitrobenzene," Materials Research Bulletin, vol. 104, pp. 15-19, 2018.

[3] Y. Yuan, B. Xi, X. He et al., "Compost-derived humic acids as regulators for reductive degradation of nitrobenzene," Journal of Hazardous Materials, vol. 339, pp. 378-384, 2017.

[4] S. Zhou, K. You, H. Gao et al., "Mesoporous silicaimmobilized $\mathrm{FeCl}_{3}$ as a highly efficient and recyclable catalyst for the nitration of benzene with $\mathrm{NO}_{2}$ to nitrobenzene," Molecular Catalysis, vol. 433, pp. 91-99, 2017.

[5] G. Olah, R. Malhotra, and S. Narang, Nitration: Methods and Mechanism, VCH Publishers, New York, NY, USA, 1989.

[6] V. V. Brei, S. V. Prudius, and O. V. Melezhyk, "Vapour-phase nitration of benzene over superacid $\mathrm{WO}_{3} / \mathrm{ZrO}_{2}$ catalysts," Applied Catalysis A: General, vol. 239, no. 1-2, pp. 11-16, 2003.

[7] P. A. Quadros, N. M. C. Oliveira, and C. M. S. G. Baptista, "Benzene nitration: validation of heterogeneous reaction models," Chemical Engineering Science, vol. 59, no. 22-23, pp. 5449-5454, 2004.

[8] A. P. Koskin, R. V. Kenzhin, A. A. Vedyagin, and I. V. Mishakov, "Sulfated perfluoropolymer-CNF composite as a gas-phase benzene nitration catalyst," Catalysis Communications, vol. 53, pp. 83-86, 2014.

[9] A. P. Koskin, I. V. Mishakov, and A. A. Vedyagin, "In search of efficient catalysts and appropriate reaction conditions for gas phase nitration of benzene," Resource-Efficient Technologies, vol. 2, no. 3, pp. 118-125, 2016.

[10] J. Li, J. Yang, M. Wang, Y. Lu, and M. He, "A microreactor based on sinter-locked microfibrous media with open porous structure for nitration of benzene," Chinese Journal of $\mathrm{Ca}$ talysis, vol. 28, no. 11, pp. 931-933, 2007.

[11] D. Vassena, A. Kogelbauer, and R. Prins, "Potential routes for the nitration of toluene and nitrotoluene with solid acids," Catalysis Today, vol. 60, no. 3-4, pp. 275-287, 2000.

[12] A. M. Silva and M. A. C. Nascimento, "A DFT study of nitration of benzene by acyl nitrate catalyzed by zeolites," Chemical Physics Letters, vol. 393, no. 1-3, pp. 173-178, 2004.

[13] S. Gong, L. Liu, Q. Cui, and J. Ding, "Liquid phase nitration of benzene over supported ammonium salt of 12-molybdophosphoric acid catalysts prepared by sol-gel method," 
Journal of Hazardous Materials, vol. 178, no. 1-3, pp. 404-408, 2010.

[14] A. Greish, "Nitration of aromatic hydrocarbons over heterogeneous catalysts," Russian Journal of General Chemistry, vol. 48, pp. 92-104, 2004.

[15] P. A. Quadros, N. M. C. Oliveira, and C. M. S. G. Baptista, "Continuous adiabatic industrial benzene nitration with mixed acid at a pilot plant scale," Chemical Engineering Journal, vol. 108, no. 1-2, pp. 1-11, 2005.

[16] N. C. Deno and R. Stein, "Carbonium ions. III. Aromatic nitration and the C0Acidity function1," Journal of the American Chemical Society, vol. 78, no. 3, pp. 578-581, 1956.

[17] F. Giacalone, P. Catrini, A. Tamburini, A. Cipollina, A. Piacentino, and G. Micale, "Exergy analysis of reverse electrodialysis," Energy Conversion and Management, vol. 164, pp. 588-602, 2018.

[18] Y. Peralta-Ruiz, A.-D. González-Delgado, and V. Kafarov, "Evaluation of alternatives for microalgae oil extraction based on exergy analysis," Applied Energy, vol. 101, pp. 226-236, 2013.

[19] H. Jawad, M. Y. Jaber, and R. Y. Nuwayhid, "Improving supply chain sustainability using exergy analysis," European Journal of Operational Research, vol. 269, no. 1, pp. 258-271, 2018.

[20] P. L. Cruz, Z. Navas-Anguita, D. Iribarren, and J. Dufour, "Exergy analysis of hydrogen production via biogas dry reforming," International Journal of Hydrogen Energy, vol. 43, no. 26, pp. 11688-11695, 2018.

[21] R. Ayres, L. Ayres, and K. Martinas, EcoThermodynamics: Exergy \& Life Cycle Analysis, INSEAD, Fontainebleau, France, 1996. 


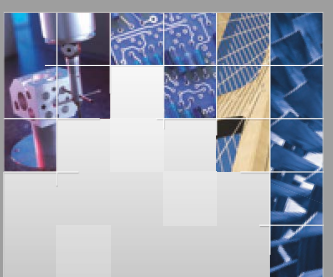

\section{Enfincering}
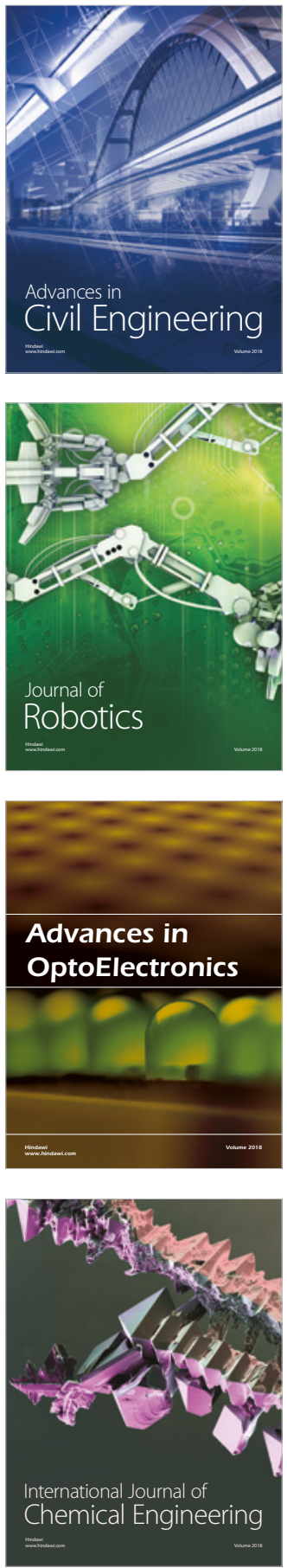

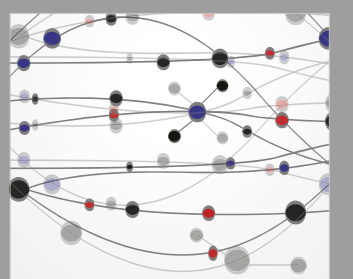

\section{Rotating \\ Machinery}

The Scientific World Journal

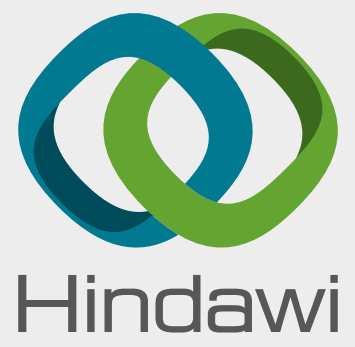

Submit your manuscripts at

www.hindawi.com
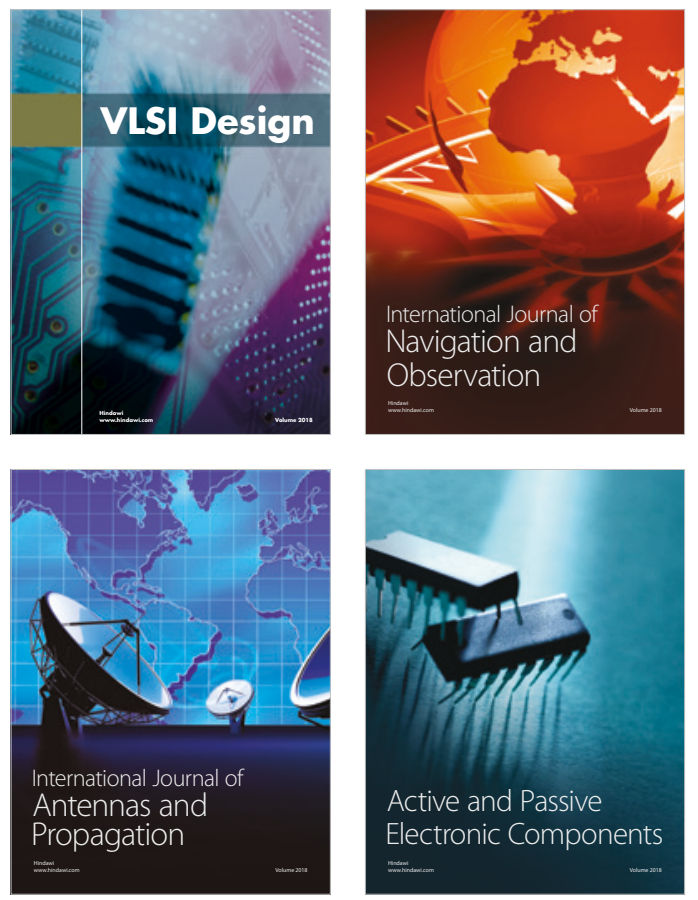
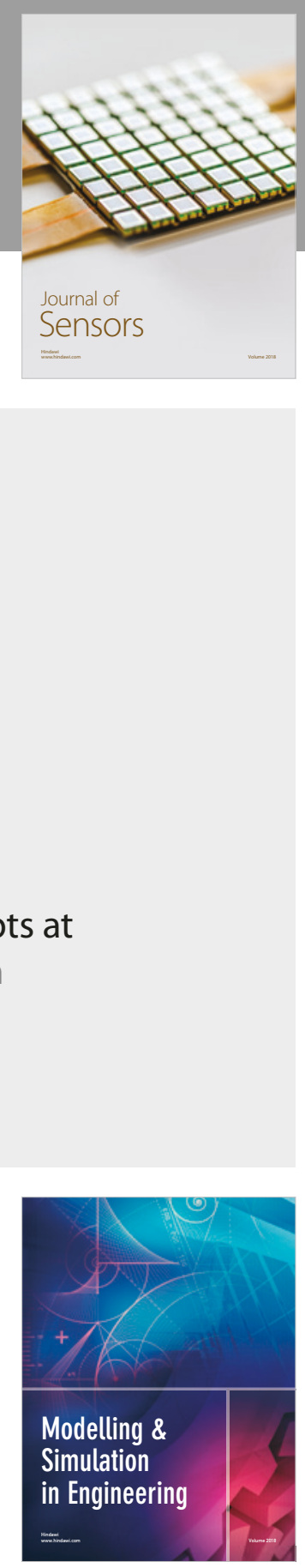

\section{Advances \\ Multimedia}
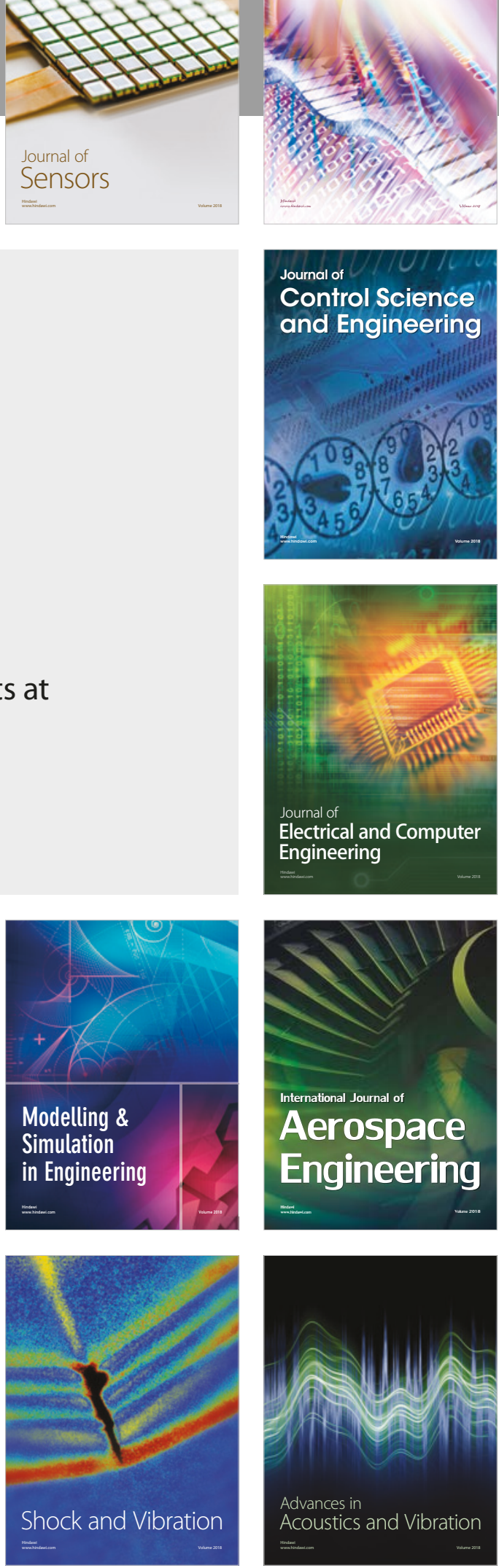